\title{
A CONSTITUIÇÃO: \\ UM GolPe Contra a OPINIÃo Pública *
}

MiKe KLARMAN $^{\dagger}$

Em meu livro, recentemente publicado, intitulado como $O$ Golpe dos Framers: a elaboração da Constituição dos Estados Unidos, procuro desenvolver três contribuições centrais para as quais já há ampla e rica literatura desde os primórdios da Constituição dos Estados Unidos da América. ${ }^{1}$ Inicialmente, procuro narrar toda a história do período da Fundação (Founding) no seguinte intervalo: a partir das falhas dos Artigos da Confederação (documento sob o qual os Estados Unidos foram governados antes de a Constituição ser promulgada); através dos conflitos interestaduais sobre políticas fiscal e monetária na metade da década de 1780, através da Convenção da Filadélfia, em que se redigiu a Constituição; através das disputas sobre a ratificação nos Estados, do debate político entre Federalistas e Antifederalistas (defensores e oponentes à ratificação, respectivamente) e da promulgação do Bill of Rights, que foi acrescido à Constituição dois anos mais tarde. Há muitos livros que discorrem sobre essa história, alguns dos quais são maravilhosos, todavia não há livro abrangente sobre o assunto. Assim, espero preencher a lacuna da literatura. Em segundo lugar, apoio-me

\footnotetext{
* Traduzido para o português, com a autorização do autor, por Antonio Guimarães Sepulveda e revisado por Igor de Lazari, do artigo inédito The Constitution as a Coup Against Public Opinion, originalmente produzido em língua inglesa. Antonio Guimarães Sepulveda é Mestre pelo Programa de Pós-Graduação em Direito (PPGD) da Universidade Federal do Rio de Janeiro (UFRJ), Doutorando em Direito pela Universidade do Estado do Rio de Janeiro (UERJ), Professor Convidado da Fundação Getúlio Vargas (FGV), do Programa de Pós-Graduação da Universidade Federal Fluminense (UFF) e da Escola de Administração Fazendária (ESAF) e Pesquisador do Laboratório de Estudos Teóricos e Analíticos sobre o Comportamento Institucional (LETACI). E-mail: antonioguisep@gmail.com. Igor de Lazari é mestrando pelo Programa de Pós-Graduação em Direito (PPGD) da Universidade Federal do Rio de Janeiro (UFRJ) e Pesquisador do Laboratório de Estudos Teóricos e Analíticos sobre o Comportamento das Instituições (LETACI). E-mail: rogi.242006@hotmail.com. $\dagger$ Professor Kirkland \& Ellis da Universidade de Harvard. É autor da obra intitulada The Framers' Coup: The Making of the United States Constitution, publicada, em 2016, pela Oxford University Press.

${ }^{1}$ KLARMAN, Michael. The Framer's Coup: the Making of the United States Constitution. New York, NY: Oxford University Press, 2016.
} 
bastante em fontes primárias, que me possibilitam contar a história principalmente nas palavras dos participantes. Espero elaborar um livro mais vibrante e também que os leitores decidam por si próprios sobre o quanto minhas interpretações são persuasivas. Finalmente e em terceiro lugar, procurei oferecer uma nítida margem para a história da "contrarrevolução conservadora", que muitos historiadores narram sobre a Fundação (Founding) - ou seja, apresentar a Constituição como uma contrarrevolução conservadora às tendências igualitárias e redistributivas desencadeadas ou aceleradas pela Guerra Revolucionária.

Nesse breve artigo, discutirei três dos temas que sustentam o livro $O$ Golpe dos Framers. Em primeiro lugar, vou descrever duas maneiras pelas quais a Constituição se tornou muito diferente daquilo que a maioria dos americanos queriam ou esperavam da Convenção da Filadélfia: o grau mediante o qual se deslocou o poder dos níveis estadual e local para o nível nacional (chame de aspectos "nacionalizadores" da Constituição) e o grau a partir do qual se procurou constranger a direta influência popular sobre o governo nacional (designe de aspectos constitucionais "antipopulistas" ou "democráticos-restritivos"). Em segundo lugar, tentarei explicar o porquê de se ter escrito tal documento na Convenção da Filadélfia. Em terceiro, explorarei como os pais-fundadores (Framers) conseguiram convencer o povo norte-americano a ratificar a Constituição - por meio de um processo que era razoavelmente democrático para aquela época (reconhecendo a óbvia ausência de qualificação para participar das mulheres, dos negros, dos nativos americanos e da população sem propriedade) - que substancialmente reduziu a ordinária influência popular sobre o governo nacional.

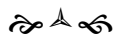

Para começar, então, a Constituição continha várias características surpreendentemente nacionalistas. Em primeiro lugar, concedia ao Congresso, praticamente, ilimitado poder de tributar - em total contraste com os Artigos da Confederação, sob o qual o Congresso Nacional não exerceu qualquer poder coercitivo de tributar, mas somente deteve poder de requisitar fundos aos Estados, os quais frequentemente declinavam de pagar. Por duas vezes, na vigência dos Artigos da Confederação, o Congresso propôs emendas que concediam poder de impor obrigações nas operações de importação. Todavia, em cada episódio, um Estado (primeiro Rhode Island e, mais tarde, Nova Iorque) rejeitou a proposta, impedindo a obtenção da unanimidade requerida para a aprovação de 
emenda aos Artigos da Confederação. A Constituição, em contrapartida, delegou poderes ao Congresso para majorar qualquer espécie tributária - inclusive os controversos tributos, a saber, land tax e head tax -, praticamente de forma ilimitada.

Em segundo lugar, a Constituição deferiu ao Congresso praticamente ilimitados poderes militares - de criar o exército e a marinha e convocar as milícias estaduais para o serviço federal. Mesmo em tempo de paz, o Congresso foi autorizado a aumentar o exército, sem limites quanto ao tamanho e sem imposição de qualquer requerimento de aprovação de supermaiorias congressuais. Em contraste, sob a vigência dos Artigos da Confederação, o Congresso podia apenas requisitar tropas estaduais.

Em terceiro lugar, a Constituição outorgou ilimitados poderes ao Congresso para regular o comércio interestadual e exterior. Tal poder não existia sob o pálio dos Artigos da Confederação.

Em quarto lugar, a Constituição atribuiu poderes implícitos ao Congresso. Especificamente, a Cláusula Elástica (the Necessary and Proper Clause) estipula que o Congresso pode exercer, em acréscimo aos seus vários poderes expressamente enumerados, aqueles poderes que sejam "necessários e adequados" para execução de seus poderes especificados. Contrariamente, sob a égide dos Artigos da Confederação, o Congresso estava explicitamente limitado, podendo exercer tão somente os poderes "expressamente delegados". Enquanto a Cláusula Elástica se revelou intensamente controversa durante a disputa da ratificação, ela foi aprovada unanimemente pela Convenção da Filadélfia.

Finalmente e em quinto lugar, a Constituição ofereceu marcante declaração teórica da supremacia federal e forneceu os instrumentos práticos para sua execução - ambas as disposições normativas não possuíam previsão nos Artigos da Confederação. Por exemplo, os Artigos claramente autorizaram o Congresso da Confederação a negociar tratados, apesar de o Parlamento não possuir os meios de execução das disposições dos tratados em relação aos Estados recalcitrantes que ignorassem normas desvantajosas.

Na Convenção da Filadélfia, Madison propôs um mecanismo de execução da supremacia federal: o Congresso seria investido de absoluta autoridade para vetar qualquer lei estadual. Nem remotamente algo do gênero havia sido publicamente proposto e essa ideia provou ser por demais nacionalista até mesmo para um grupo de delegados nacionalistas.

Em lugar da proposta madisoniana de veto nacional, a Convenção adotou um mecanismo tripartite para a aplicação da supremacia federal. A Cláusula da Supremacia do Artigo VI esclareceu que lei federal de qualquer natureza - a Constituição, leis federais e tratados internacionais 
- superaria lei estadual. A Cláusula III criou a Suprema Corte e autorizou - todavia não exigiu - o Congresso a criar tribunais federais inferiores. Contrariamente, não havia previsão de cortes federais de competência geral sob a vigência dos Artigos da Confederação. Finalmente, a Seção 10 da Cláusula I estabeleceu regra substantiva, de âmbito federal, para impedir que Estados adotassem o tipo de lei sobre emissão de papelmoeda e medidas de socorro a devedores que havia chocado várias elites políticas, em meados da década de 1780, e tinha desempenhado, em primeiro lugar, uma função crítica na elaboração da Convenção da Filadélfia.

Vale destacar que a maioria dos Estados promulgaram legislação afeta a socorros tributários e financeiros e editaram leis relativas à emissão de papel-moeda nos primeiros dois anos que precederam a Convenção da Filadélfia. Como os delegados da Convenção aprovaram unanimemente a Seção 10 da Cláusula I, tal fato diz muito sobre como a população americana na Convenção foi, em termos gerais, subrepresentada.

A Seção 10 da Cláusula I tanto foi uma característica nacionalizadora da Constituição - autorizando o governo nacional a bloquear a legislação estadual de certa espécie - quanto um traço antipopulista. Outros centrais mecanismos constitucionais antipopulistas foram os extensos mandatos estabelecidos para os titulares de cargos federais. Sob pálio dos Artigos da Confederação e na maior parte das constituições estaduais, legisladores exerciam mandatos anuais; membros da Câmara cumpriam suas atribuições por dois anos; presidentes, por quatro; e senadores, por seis anos.

De fato, muitos dos delegados na Convenção da Filadélfia teriam preferido mandatos mais longos para o exercício de cargos federais, se não tivessem sido constrangidos por exigências práticas da ratificação. A Convenção estabeleceu provisoriamente que representantes exerceriam mandatos trienais. Madison e outros delegados preferiam mandatos de nove anos para senadores. Delegações de quatro Estados votaram em favor de mandatos vitalícios presidenciais. Alexander Hamilton apoiava mandatos vitalícios tanto para presidentes quanto para senadores, sustentando que direitos de propriedade somente poderiam ser adequadamente protegidos mediante extensos mandatos.

Eleição indireta para cargos federais era outra característica constitucional de restrição democrática. Juízes federais seriam indicados pelo Presidente e submetidos à confirmação senatorial. Legislaturas estaduais escolheriam os senadores federais (até a décima sétima emenda que fora ratificada em 1913). Presidentes seriam escolhidos por eleitores que fossem selecionados de uma forma determinada pelas legislaturas estaduais (a qual, atualmente, significa pelo voto popular, mas que para 
muitos dos delegados da Convenção da Filadélfia significou outra coisa).

A maior parte dos pais-fundadores (Framers) não confiavam nos americanos comuns para escolher seus líderes políticos. Na Convenção, George Mason, um importante delegado da Virgínia, declarou que "seria tão abnormal delegar ao povo a escolha de um adequado indivíduo para magistrado-chefe quanto delegar o julgamento de cores a um homem cego".

Os Framers projetaram ainda um ramo do governo nacional que era para ser popularmente eleito e cujos membros exercessem relativamente curtos mandatos no cargo. A Câmara era para ser isolada tanto quanto possível da influência política populista. A Constituição proporcionou, de início, uma Câmara muito pequena - significando que os representantes individuais teriam um amplo número de eleitores dispersos sobre uma extensa área geográfica. O objetivo desse arranjo era duplo. Primeiro, asseguraria que o "melhor tipo" - pessoa relativamente abastada, bem educada e ligada à elite bem-nascida - seria eleito para o cargo. E, em segundo lugar, enfraqueceria a conexão entre eleitores e seus representantes parlamentares, permitindo aos últimos "refinar e ampliar" - de acordo com as palavras de Madison - as pretéritas visões.

A originária Câmara conteria somente 65 (sessenta e cinco) representantes, que traduziriam a relação de mais de 30.000 (trezentos mil) eleitores para cada membro da Casa. Contrariamente, a Casa baixa da legislatura de Massachusetts dispunha de bem mais, entre os anos de 1787 e 1788, de 300 (trezentos) membros, cada qual representando menos do que 1.500 (mil e quinhentos) eleitores.

Além disso, a Seção 4 da Cláusula I da Constituição autorizou o Congresso a revisar as regulações estaduais acerca de prazos, locais e formas das eleições parlamentares. Muitos pais-fundadores (Framers) consideraram que o Congresso usaria tal poder para insistir que Estados selecionassem "amplamente" seus representantes parlamentares. Com base em tal disposição, por exemplo, o Congresso poderia requerer que dez representantes parlamentares de Virgínia fossem votados por todos os cidadãos e representassem o Estado inteiro. Eleições amplas se traduziriam, é claro, em enormes bases geográficas eleitorais, as quais os Framers assumiam que garantiriam a eleição dos "melhores" e reduziria a dependência representativa de seus eleitores.

Finalmente, a Constituição omitiu disposições relacionadas com mecanismos de instrução de reforço democrático, de alternância no cargo e de recall. "Instrução" habilita eleitores a instruir seus representantes a como votar em específicos assuntos debatidos na legislatura (sob pena de ser forçado a renunciar por violar as instruções). "Recall" proporciona, por exemplo, que as legislaturas estaduais, sob o pálio dos Artigos da 
Confederação, removam dos cargos seus representantes parlamentares, ainda que anteriormente ao término do mandato. A "alternância no cargo" impunha limites temporais ao exercício do mandato para legisladores e governantes. Por exemplo, sob a vigência dos Artigos, delegados congressuais exerceriam o mandato por apenas três anos a cada seis. A Constituição omitiu cada um desses mecanismos de reforço democrático, que figuraram em várias constituições estaduais e nos Artigos da Confederação.

Em suma, os pais-fundadores (Framers) introduziram na Constituição vários recursos democrático-restritivos (e omitiram vários recursos de reforço democrático). Os propósitos em fazê-lo foi assegurar que o governo federal nunca concordaria com leis promulgadas por legislaturas estaduais, em meados da década de 1870, relativas à emissão de papel-moeda e de socorro a devedores, impedido que os governos estaduais aprovassem tais medidas novamente no futuro.

$$
\text { 2A }
$$

Como a Convenção da Filadélfia lidou com a redação de uma Constituição tão diferente daquilo que a maioria dos americanos esperavam e provavelmente desejavam e como os Federalistas conduziram o país a ratificar tal documento? Essas são as partes do livro em que tento, como já anotado, expressar nítida margem de interpretação da Constituição como uma "contrarrevolução conservadora" em contraste com as tendências igualitárias e redistributivas desencadeadas pela Revolução.

Um proeminente crítico contemporâneo da Constituição afirmou com precisão, eu penso - que "as partes democráticas e aristocráticas da comunidade foram desproporcionalmente representadas na Filadélfia". Aqui estão vários pontos específicos que podem, em conjunto, equivaler a uma explicação de o porquê ter sido esse o caso.

Em primeiro lugar, todos os Estados que escolheram enviar delegados à Convenção da Filadélfia - somente Rhode Island não participou - os legisladores estaduais selecionaram aqueles delegados (a única exceção foi Carolina do Sul, em que o governador os escolheu). A maioria das legislaturas parece simplesmente ter escolhido os mais eminentes cidadãos de seus Estados. Por exemplo, Virginia indicou como delegados, entre outros, George Washington, Patrick Henry, George Mason e James Madison. Os mais eminentes cidadãos estaduais, por sua vez, tendiam a ter atuado no Congresso da Confederação ou no Exército Revolucionário, 
ou em ambos. Serviço de uma ou outra espécie era profundamente uma experiência de nacionalização. Representantes de uma legislatura nacional frequentemente tendiam a pensar nacionalmente ao invés de provincianamente. Servir no exército, em guerra, para constituir uma nação - e enfrentar severos obstáculos, não só advindos dos soldados britânicos como também das legislaturas estaduais nada cooperativas - é uma experiência de nacionalização. Semelhantemente, os eminentes cidadãos, provavelmente escolhidos pelas legislaturas para representar seus Estados em uma importante convenção nacional, seriam razoavelmente prósperos e bem educados - características relacionadas, em 1787, com a hostilidade à influência populista no governo.

Em segundo lugar, opositores ao projeto de nacionalizaçãoantipopulista tinham pouca razão para se mobilizarem contra a Convenção da Filadélfia, porque não tinham como saber o que lá aconteceria. A agenda da Convenção, constatou-se, estava principalmente na mente de um único homem - James Madison. O jovem de Virginia não era o mais ilustre dos delegados na Convenção, longe disso. Todavia, ele era o único delegado que, antes da elaboração da convenção, tinha estudado sistematicamente a história das confederações e as falhas dos Artigos da Confederação e das constituições estaduais, bem como propôs remédios para aquelas falhas. Madison, então, encorajou os delegados de Virginia a chegarem cedo à Filadélfia, onde poderiam se coordenar entre si e com os delegados da Pensilvânia, que, convenientemente, residiam na Filadélfia. A consequência desses esforços foi o nacionalista e democrático-restritivo Plano de Virginia, que se tornou modelo de trabalho da Convenção. Embora Madison estivesse decepcionado com várias decisões tomadas durante a Convenção da Filadélfia, importou-se significativamente com o resultado final, obtido a partir das deliberações pautadas, desde o início da Convenção, nas resoluções do Plano de Virginia.

Um terceiro fator auxiliar a explicar a natureza não representativa da Convenção foi a decisão de oito ou dez delegados que haviam sido indicados por suas legislaturas de declinar de suas nomeações. Alguns desses homens - incluindo Patrick Henry e Richard Henry Lee, da Virginia, e Samuel Chase, de Maryland, tornaram-se líderes antifederalistas durante a disputa da ratificação.

É difícil saber com segurança o porquê desses homens terem declinado de suas nomeações à Convenção. Alguns deles não ofereceram nenhuma explicação para suas decisões; para os outros, suas declarações podem não ter se baseado em verdadeiras razões para não participarem. Uma possibilidade - ainda que, reconhecidamente, especulativa - é que esses indivíduos não estavam interessados em um projeto moderado de 
nacionalização. Provavelmente, eles falharam ao desconfiar que um radical movimento de reforma estava em curso. Tivessem cientes do que Madison e outros tinham em mente para a Convenção, talvez eles se inclinariam a participar a fim de lutar contra tal projeto.

Em quarto lugar, poucos delegados que participaram da Convenção da Filadélfia, mas não tinham apoio em sua agenda de nacionalizaçãoantipopulista, tomaram a importante decisão de retirar-se cedo. Entre esses delegados estavam Luther Martin, de Maryland, e Robert Yates e John Lansing Jr., de Nova Iorque (cuja precoce retirada de Filadélfia teve o efeito de nulificar o voto da delegação de Nova Iorque, assim incitando seu terceiro membro, Alexander Hamilton, também a deixar a Filadélfia antecipadamente). Os delegados que prematuramente se retiraram fizeram plausível cálculo de que remanescer na Filadélfia ajudaria a legitimar um empreendimento que não estava autorizado pelos Artigos da Confederação e que teria excedido suas iniciais instruções restritivas. Entretanto, por se retirarem prematuramente, esses delegados essencialmente asseguraram que o trabalho definitivo da Convenção desviasse mais além de suas preferências.

Em quinto lugar, os delegados na Filadélfia tomaram a crucial decisão de fechar as portas da Convenção à imprensa e ao público, e de realizar rigoroso juramento de confidencialidade. Os delegados tinham boas razões para essa decisão. Como Madison explicou posteriormente, provavelmente não haveria nenhuma Constituição caso tivessem aberto a Convenção ao público. Contudo, um importante efeito de fechar as portas da Assembleia da Pensilvânia foi permitir que delegados exprimissem visões extremamente nacionalistas e antipopulistas posições que teriam comprometido suas carreiras políticas se as tivessem afirmado publicamente. Talvez de igual importância, por encobrir da opinião pública as deliberações da Convenção, os delegados retardaram por vários meses a mobilização da oposição dos antifederalistas à Constituição.

Finalmente, os delegados fizeram uma importante escolha para aproveitar o momento e prosseguir numa reforma de longo alcance. Em correspondência trocada antes da Convenção, Madison e George Washington se deleitaram ao descobrir que eles compartilhavam a visão de que a Convenção da Filadélfia deveria evitar "recursos temporizadores". Igualmente, quando o governador de Virginia, Edmund Randolph, lançou antecipadamente o Plano Virginia na Convenção, ele declarou - de acordo com as notas de Madison - que "não dependeria dele [Randolph] deixar nada que parecesse necessário desfazer. O presente momento é favorável e é provavelmente o último que oferecerá". Em suma, os Framers decidiram investir maciçamente. 
Talvez eles não tivessem outra chance de perseguir o tipo de reforma radical que acreditavam ser necessária para garantir um bom governo nacional.

$$
2 \Delta \alpha
$$

Passando para o meu último assunto, pergunto como os paisfundadores (Framers) conseguiram convencer a nação a aprovar - em razoável processo democrático de ratificação - a Constituição que fora desenhada, em parte, para despojar o povo comum da relevante influência sobre seu próprio governo nacional?

Antes de procurar explicar esse enigma, deixe-me primeiro destacar que a ratificação da Constituição foi de forma alguma inevitável. Foi um contexto de luta acirrada. Rhode Island e Carolina do Norte inicialmente rejeitaram ratificar e New Hampshire teria provavelmente também feito o mesmo caso não tivessem os Federalistas habilmente interrompido, antes da coleta do voto final, a sessão inicial da convenção de ratificação dos Estados. Além disso, os votos das Convenções em três dos cinco mais populosos Estados foram apertadamente em favor da ratificação - 89 votos a favor e 79 votos contra a ratificação na Virginia; 187 a 168, em Massachusetts, e 30 a 27, em Nova Iorque - um resultado oposto era obviamente possível nesses Estados. Tivesse apenas um ou dois desses expressivos Estados se recusado a se unir à nova união, o sucesso se tornaria muito duvidoso.

Federalistas possuíam uma série de vantagens na disputa da ratificação; não era inteiramente uma luta justa.

Primeiramente, algumas convenções de ratificação tiveram injustas distribuições de parlamentares, de modo que a causa Federalista foi ajudada. Isso foi especialmente verdadeiro na Carolina do Sul, em que $20 \%$ (vinte por cento) da população branca que vivia em distritos litorâneos e onde o apoio à Constituição era muito forte elegeram $60 \%$ (sessenta por cento) dos delegados da convenção de ratificação do Estado. A maior parte dos historiadores acreditam que a maioria dos votantes elegíveis da Carolina do Sul teria se oposto à ratificação em um referendum. Todavia, a convenção de ratificação, severamente mal distribuída, aprovou a Constituição com margem de 2 (dois) para 1 (um).

Em segundo lugar, a imprensa favoreceu veementemente a ratificação. Enquanto 90\% (noventa por cento) dos americanos viviam fora das cidades em 1787, os jornais eram publicados em sua maior parte 
exclusivamente nas cidades, onde seus agentes econômicos - anunciantes e assinantes - esmagadoramente apoiaram a Constituição. Em muitos Estados, antifederalistas enfrentaram momentos de dificuldade mesmo conseguindo a publicação de seus argumentos. Nas palavras de Aedanus Burke, líder antifederalista da Carolina do Sul, "todo peso e influência da imprensa estava sobre o lado da Constituição". Somente 12 (doze) de aproximadamente 90 (noventa) jornais, então em circulação, publicaram um pouco da significativa quantidade da literatura antifederalista".

Em terceiro, várias convenções estaduais de ratificação foram realizadas em cidades do leste - por exemplo, a Convenção de Massachusetts se deu em Boston; a da Pensilvânia, na Filadélfia, e da Carolina do Sul, em Charleston - onde o apoio para a Constituição era quase generalizado, mesmo através das classes sociais. Por exemplo, na cidade de Nova Iorque, 19 (dezenove) de cada 20 (vinte) votantes participantes na seleção dos delegados na convenção estadual de ratificação (reunida em Poughkeepsie) elegeram candidatos Federalistas.

Situar essas convenções em cidades do leste causava tanto um efeito interno quanto um efeito externo às convenções. Todas as convenções estaduais de ratificação foram abertas ao público e os espectadores nas galerias não se envergonhavam de expressar suas opiniões. Por exemplo, em Connecticut, os Federalistas, que dominavam a multidão, assobiavam, vaiavam e pisoteavam com seus pés quando os delegados antifederalistas se levantavam para discursar. Na Convenção da Carolina do Sul, onde delegados a interromperam ao anoitecer para sessões abertas patrocinadas pela elite de agricultores de Charleston, eles certamente nada ouviram, exceto amáveis palavras, sussurradas em seus ouvidos, sobre a Constituição.

A quarta vantagem Federalista na disputa da ratificação era a relativa facilidade com que Federalistas foram capazes de organizar seus apoiadores, que viviam desproporcionalmente em cidades e ao longo da costa leste. Em contrapartida, antifederalistas incorreram em grande dificuldade - numa era de relativamente primitivos transporte e comunicação - de organizar seus adeptos, os quais viviam principalmente no oeste e em distritos rurais, escassamente povoados e desconectados das redes comerciais. Mesmo que os dois lados da disputa tivessem similares números de adeptos - o que aproximadamente é o que a maioria dos historiadores tem estimado ter sido o caso - Federalistas gozavam de uma clara vantagem organizacional.

Quinto, o "melhor tipo" - a elite relativamente abastada, bem educada e bem nascida - majoritariamente apoiou a ratificação em todo lugar, exceto na Virginia, onde a elite era mais uniformemente dividida. Essa diferença da elite de sustentação deu aos Federalistas uma real vantagem 
oratória, visto que nenhum delegado chegou à Convenção de ratificação com a mente aberta (o que aconteceu em alguns Estados). Agricultores de Backwoods não puderam citar Cícero no original em latim e frequentemente foram intimidados de falar diante de seus oponentes, mais educados e talentosos oradores. Assim, por exemplo, na Convenção de ratificação de Massachusetts, o antifederalista Amos Singletary queixou-se "[d]estes advogados, dos homens educados e dos homens endinheirados que falam tão finamente e encobrem assuntos tão agradavelmente, fazendo-nos pobres pessoas iletradas a aceitar".

Finalmente, em sexto lugar, a Cláusula VII da Constituição foi uma enorme vantagem para os Federalistas, que, é claro, tinham elaborado esse dispositivo para eles mesmos. Enquanto os Artigos da Confederação requeriam aprovação unânime dos Estados para promulgação - que, na prática, houvera provado ser de impossível alcance - a Cláusula VII previu que a ratificação por nove Estados colocaria a Constituição em vigência (embora nenhum Estado se vinculasse a nova união sem o próprio consentimento).

Essa alteração das regras para alterar o sistema de governo norteamericano, que os Framers, na Filadélfia, simplesmente estabeleceram (e que esperavam poder afastar) modificou dramaticamente o equilíbrio de poder, para longe dos potenciais Estados discordantes. Por exemplo, sob a égide dos Artigos, quando Nova Iorque, em 1786, foi o último Estado a resistir à ratificação da proposta de emenda que autorizaria o Congresso a impor encargos na importação, a legislatura nova-iorquina procurou obter concessões do Congresso (v.g., aceitar como pagamento devido pelo Estado de Nova Iorque, referente àqueles encargos na importação, o papel-moeda emitido pelo próprio Estado) em troca do apoio novaiorquino à emenda. Contrariamente, sob a Constituição, uma vez que nove Estados tivessem ratificado, os quatro Estados remanescentes não teriam outra opção, por questão prática, a não ser se alinharem. Aos Estados discordantes poderia ser negada proteção militar, poderiam ser submetidos a sanções comerciais discriminatórias e perderiam a oportunidade de participar de decisões fundamentais a serem tomadas pelo primeiro Congresso, tais como, onde se situar a definitiva capital do país e se Constituição deveria ser emendada com um Bill of Rights.

Em acréscimo, para beneficiar o desigual campo de ação, os Federalistas também se favoreceram de alguns erros de cálculos dos antifederalistas, especialmente em Nova Iorque e Virginia. Em ambos Estados, muitos antifederalistas apoiaram tardiamente as convenções de ratificação. Ambas as convenções estaduais se reuniram em junho de 1788, nove meses após a Convenção Constitucional ter-se encerrado. Nesses Estados, os Antifederalistas provavelmente calcularam que 
poderiam se beneficiar de um tempo adicional para organizar seus adeptos e, talvez, tenham também acreditado, por atrasar suas decisões, que seus Estados desempenhariam uma função mais influente na determinação do resultado da disputa nacional de ratificação.

Tais atrasos, ao invés, tornaram esses Estados irrelevantes para o resultado da disputa. Quando Virginia aprovou a Constituição, no tardio mês de junho, e Nova Iorque o fez, então, no tardio mês de julho, nove Estados já tinham ratificado e, assim, posto a Constituição em vigência (as notícias circulavam tão lentamente naqueles dias que os delegados de Virginia não sabiam sobre a ratificação de New Hampshire - o nono Estado a aprovar a Constituição - mesmo após a Convenção de Richmond ter-se encerrado). Tivesse Nova Iorque ou Virginia realizado sua convenção mais cedo ou rejeitado incondicionalmente a ratificação - que teria sido provável -, a dinâmica em direção à ratificação teria sido perturbada e possivelmente influenciado as decisões de outros Estados.

Último fator de sucesso dos Federalistas foi a determinação e a capacidade de manter fora de discussão opções intermediárias, forçando, assim, o país a escolher entre obviamente o defeituoso Artigos da Confederação e a muito questionada Constituição. A maioria dos americanos provavelmente teria favorecido algo entre aquelas opções disponíveis a eles. Os dois instrumentos procedimentais que produziriam, mais provavelmente, uma opção intermediária seriam a ratificação estadual condicional, depois da promulgação de prévias emendas, e a convocação de uma segunda convenção constitucional.

Antifederalistas se esforçaram por uma ratificação condicional, argumentando que seus oponentes teriam poucos incentivos para cumprir suas promessas de apoio a emendas assim que incondicionalmente ratificada a Constituição. Por exemplo, Patrick Henry relatou, na Convenção de ratificação, que: "eu deveria ser levado a considerar aquele homem um lunático, o que me diz a adotar um governo declaradamente defeituoso na esperança de tê-lo emendado posteriormente". Uma segunda convenção era desejável, de acordo com um antifederalista da Carolina do Sul, porque "o sentido geral da América parecia bem compreendido" e "cada objeção [à Constituição] poderia ser atendida sobre razoáveis bases, e apropriados remédios aplicados quando necessário".

Federalistas formularam argumentos legais e práticos contra a ratificação condicional e a segunda convenção, todavia tais argumentos podem não ter sido as verdadeiras razões de se opor àqueles mecanismos procedimentais. Os Federalistas compreenderam que provavelmente não duplicariam as circunstâncias da Convenção da Filadélfia agora que as verdadeiras intenções tinha sido reveladas. O objetivo era assegurar a 
ratificação da Constituição escrita na Filadélfia e não alcançar um compromisso que refletisse as preferências da maioria dos americanos.

A esse respeito, considere a proposta que o governador Edmund Randolph fez a James Madison em carta escrita antes da Convenção da Filadélfia. A Constituição a ser elaborada, Randolph argumentou, deveria ser apresentada ao país de maneira a permitir que suas disposições fossem "separadas uma das outras de modo a permitir que um Estado rejeitasse uma parte sem mutilar o todo". Madison estava desanimado com essa proposta, porque duvidava - como fizera a maioria dos políticos da elite do país - que o povo americano fosse suficientemente desapaixonado, sábio ou bem-informado para exercer o responsável papel de conceber seu próprio sistema nacional de governo. Como Madison disse a Jefferson no fim de 1787, “em Virginia, onde a massa do povo tinha se acostumado a ser guiada por seus governantes sobre todas novas e intrincadas questões", o assunto de se ratificar a Constituição "certamente supera a capacidade de julgamento de maior parte delas".

Para resumir, então, a Constituição foi muito mais nacionalista e antipopulista do que a maioria dos americanos provavelmente previa ou desejava. Os pais-fundadores (Framers) tiraram proveito do elemento surpresa para obtê-la elaborada e os Federalistas, então, apenas persuadiram o país a ratificá-la, beneficiando-se de algumas vantagens circunstanciais, de alguns erros de cálculo de seus adversários e de alguma sorte (que, em parte, criaram para si mesmos). Se alguém concorda ou não com o que eles fizeram ou considera isso legítimo ou ilegítimo, não podemos ajudar, exceto admirar a competência em executar o que pode ser somente descrito como um golpe contra a opinião pública.

A Constituição: um golpe contra a opinião pública The Constitution as a coup against public opinion Submetido em: 2017-05-04 Aceito em: 2017-07-29 